\title{
Les nou preguntes que Norbert Elias es va formular: debats, interrogants i pistes per a la sociologia del segle XXI
}

\author{
Jordi Collet-Sabé
}

Facultat d'Educació. Universitat de Vic.

IGOP Institut de Govern i Polítiques Públiques. Universitat Autònoma de Barcelona jordi.collet@uvic.cat

Joan Estruch

Departament de Sociologia. Universitat Autònoma de Barcelona joan.estruch@uab.cat

\section{Resum}

En aquest article dedicat a Norbert Elias en commemoració dels vint anys de la seva mort, proposem revisar, de manera resumida, la seva obra a partir dels interrogants ontològics, epistemològics i metodològics que Elias va encarar al llarg de la seva dilatada vida acadèmica i de recerca. Larticle pretén ser, alhora, un punt i a part en el monogràfic, perquè en vol recollir alguns dels interrogants, debats i conclusions, com també tenir un paper introductori per a aquelles persones que, sense gaires coneixements previs sobre l'autor de Breslau, vulguin conèixer alguns dels trets definitoris de la seva trajectòria intel-lectual al llarg del segle XX. I, sobretot, quin llegat, en forma de grans preguntes, deixa per a la sociologia del segle XXI. L'article acaba amb una bibliografia escollida d'obres clau.

Paraules clau: teoria sociològica; procés de civilització; coneixement; poder; violència; alteritat.

Abstract. The nine issues raised by Norbert Elias: Debates, questions and clues for a sociology of the 21st century

In this last article dedicated to Norbert Elias on the occasion of the 20th anniversary of his death, we propose to revise his work in a summarized way basing ourselves on the ontological, epistemological and methodological questions which Elias took up during his extensive life of teaching and research. The article also pretends to be a halting point in the monographic by picking up some of its questions, debates and conclusions, and to serve as an introduction for all those who, without special previous information about the author from Breslau, want to acquaint themselves with some of the defining features of his intellectual career throughout the 20th century. And, above all, who want to know which legacy, in the form of important questions, he leaves to the sociology of the 21 st century. The article concludes with a selected biography of his main works.

Key words: sociological theory; civilization process; knowledge; power; violence; otherness. 


\section{Sumari}

\section{Introducció 7. Què és (la) violència?}

2. Per què, al llarg del temps i en classes 8. Qui és l'altre? socials i cultures diverses, la gent es comporta de manera diferent?

9. Qui és el malalt o la malalta?

10. A manera de conclusió: l'artesania

3. El procés de civilització ens porta a la «llibertat» o a la "presó»

4. Cos, persona i societat: determinació biològica o cultural?

5. Què és el coneixement?

6. Què fonamenta el poder personal de fer sociologia

11. Bibliografia escollida de Norbert Elias

12. Bibliografia escollida d'obres sobre Norbert Elias

13. Bibliografia de l'article i social?

\section{Introducció}

Habitualment, en els estudis de sociologia, es fa un salt en la història de la teoria sociològica entre els clàssics que Talcott Parsons va descriure com a "pares fundadors» (Karl Marx, Max Weber i Émile Durkheim) i els anys daurats del funcionalisme encapçalats pel mateix sociòleg nord-americà. Així, d'una banda, tots els sociòlegs i les sociològues contemporanis als clàssics que van quedar fora de la terna i, d'altra banda, bona part de la sociologia europea i nord-americana dels anys vint, trenta i quaranta que no cau dins del funcionalisme, acostumen a restar en l'anonimat, o, a molt estirar, formen part d'aquell conjunt d'autors i de teories que, implícitament, es consideren «menors» i que s'esmenten com a detall erudit o que resten per als darrers dies de classe per ser (mal) vistos d'una revolada. Noms com ara Alfred Schütz, Georg Simmel, Ferdinand Tönnies, Florian Znaniecki o el mateix Norbert Elias no acostumen a disposar de gaire temps en els plans d'estudi de les facultats de sociologia (amb les excepcions que calgui). I no cal dir que noms com els de Harriet Martineau, Marianne Weber o Anna Julia Cooper són difícils de trobar en els mateixos plans (Madoo Lengermann y Niebrugge-Brantley, 1998; Castillo, 2009; García de León y Fígares, 2009). És evident que educar és triar i que no es poden veure amb una certa profunditat tots els autors i les autores vinculats a la sociologia i les ciències socials dels darrers cent cinquanta anys. Alhora, però, no és menys cert que al cenyir els continguts als "pares fundadors", resten fora de programa autors i autores interessants que, sense cap mena de dubte, han fet contribucions molt valuoses a l'estudi de les relacions humanes i socials.

Un dels estudiosos que, especialment des de la seva mort l'any 1990, està vivint un procés de «recuperació» és Norbert Elias. L'autor alemany, després de dècades d'oblit, va veure com els darrers anys de la seva vida, i especialment el seu decés, el convertien en un "periferic interessant» per a la sociologia. El «(re)descobriment» de què va ser objecte i la ubicació que se’n va fer a la pri- 
mera escena de la sociologia del segle XX és encara un procés obert, però, sens dubte, va esdevenint cada vegada un autor més i més conegut, apreciat i citat, tant a Europa com a l'Amèrica Llatina. El present article vol, de manera modesta i clarament parcial, presentar algunes de les aportacions transversals del pensament i la recerca d'Elias, per tal que puguin ser debatudes i apropiades de manera crítica per la sociologia del segle XXI. La manera que hem triat de presentar algunes de les propostes més destacades d'Elias és en forma de pregunta, és a dir, intentant fer l'exercici d'imaginar quins interrogants i quines motivacions van moure els interessos, les recerques i els debats del clàssic alemany. Aquest exercici d'imaginació sociològica, repetim, modest, incomplet i parcial, no té cap més objectiu que fer una primera presentació d'alguns dels temes clau de l'obra de Norbert Elias als sociòlegs i a les sociòlogues del segle XXI, amb el desig que aquest primer tast els generi les ganes d'aprofundir en les fonts originals de l'autor, que, de manera resumida i escollida, presentem al final de l'article.

\section{Per què, al llarg del temps i en classes socials i cultures diverses, la gent es comporta de manera diferent?}

Per què una persona i el seu entorn social es veuen obligats a comportar-se d'una manera o altra? Per què les normativitats socials que guien l'actuació dels individus i les col-lectivitats canvien amb el temps i entre classes socials, entre cultures, territoris, etc.? Des d'on i cap a on es modifiquen? Segueixen alguna pauta, alguna regularitat en aquesta mutació o, contràriament, és atzarosa? Aquestes són algunes de les preguntes que van guiar la recerca sociològica de Norbert Elias des de la seva joventut i fins al final de la seva vida. Una recerca que el va dur a formular la seva teoria i hipòtesi més coneguda: el procés de civilització. L'autor alemany, en l'intent de comprendre el fenomen social dels canvis de normativitat, va recórrer a la història i a la perspectiva del llarg termini per tal de cercar algunes constants en aquests canvis. Segons Elias, les diferents ciències socials del segle XX han deixat de banda amb massa facilitat una mirada que inclou diversos segles $i$, sense aquesta, els costa molt més comprendre el present. El procés de civilització, amb els camins inesperats de descivilització, recivilització, etc. que presenta, és una perspectiva que, des del llarg termini, intenta retre compte, de manera inductiva i factual, dels canvis en les normativitats socials.

Segons Elias, des de la baixa edat mitjana fins als nostres dies, es dóna de manera ininterrompuda, però no lineal ni teleològica, un procés de civilització personal i social. Això implica que determinats canvis socials fan que el comportament, les emocions, les reaccions i les relacions de les persones esdevinguin més i més (auto)controlades, refinades, pacífiques, constants, etc. Una nova pauta de comportament que, en socialitzar-se, esdevé «natural» per a les noves generacions. Unes generacions joves que, al seu torn, incrementen el grau de civilització requerit per viure en societat, la qual cosa provoca, de manera no intencional, un espiral civilitzador que segueix funcionant en els nostres dies, pot- 
ser amb més virulència que mai. Elias, contra els postulats del determinisme econòmic i alhora del relativisme, creu que és imprescindible la contextualització històrica per analitzar els processos personals i socials, i genera un diàleg permanent entre els elements psicogenètics (individuals, «mentals») i els sociogenètics (col-lectius), molt ben emmarcats i documentats històricament a partir dels llibres, del llenguatge, de l'urbanisme, dels rituals, etc. de cada època. Amb aquesta contextualització històrica, Elias es pregunta en concret per les condicions de possibilitat d'un o altre comportament (cas) i, en general, per les condicions de possibilitat de l'estabilitat i el canvi de les normes personals i socials (categoria).

Per tal de no perdre la dimensió diacrònica de la realitat social, en aquest treball, l'autor de Breslau es troba en un debat ontològic que és més útil que mai en els nostres dies: el que enfronta l'experiència vital dels habitants de la modernitat líquida de ser homo clausus, és a dir, éssers cada vegada més separats, aillats i autosuficients de la resta d'individus i de la societat, contra la perspectiva sociològica i el concepte d'interdependència d'Elias. Per a l'autor alemany, és precisament en un context tan i tan civilitzat com l'actual, quan la interdependència entre les persones és més gran que mai, però, paradoxalment, quan menys es veu i sobretot quan menys es viu. Però això no ha de fer perdre de vista a la sociologia del segle XXI la necessitat de continuar comprenent les relacions socials com a vincles d'interdependència que es donen en un estadi de civilització concret. Una proposta que Elias va formular per a la «societat dels individus» sota el nom de «sociologia figurativa».

\section{El procés de civilització ens porta a la «llibertat» o a la "presó»?}

La pregunta pel sentit «moral» de la modernitat no és pas original d'Elias. Des de l'edat mitjana, els diferents pensadors havien donat una interpretació als canvis socials que es van anar vivint al llarg dels segles (inicis del capitalisme modern, urbanització, principis d'industrialització, etc.) en un sentit o altre. En relació amb el debat del renaixement sobre quina és la naturalesa humana, si és competitiva, de lluita i desconfiança o col-laborativa, de bondat i confiança, els autors dels segles XVIII, XIX i XX van expressar dos pronòstics clarament diferenciats sobre com influirien els canvis de la modernitat i els processos de civilització sobre la vida de les persones i les societats. D’una banda, Sigmund Freud o Max Weber sentien clarament que els diferents processos de la modernitat lligats a més civilització, racionalització, diferenciació, burocratització, etc. portarien els éssers humans a un futur més aviat pitjor. Ja fos via el desencantament, el fet de viure en una còmoda però freda gàbia de ferro sense sentit ni transcendència (Weber); ja fos pel camí de les angoixes, els malestars, els patiments i la manca d'alegria, en haver de coartar les diferents pulsions plaents com a preu per viure en societat, en la cultura (Freud). Des d'aquesta perspectiva, la modernitat i la civilització van aportant una mena de «maons» que construeixen una presó, una coacció, una opressió per a una naturalesa humana que, com menys socialment condicionada està, més feliç es 
troba. Per contra, en una postura gairebé només compartida amb Émile Durkheim, Norbert Elias pensava que era precisament el procés de civilització el que, construint en els éssers humans una segona naturalesa, la social, "per sobre» de l'animal, els podia fer més conscients i lliures. El raonament parteix d'una natura humana no tan «bondadosa», la qual, precisament el fet de socialitzar-la i civilitzar-la, li permet anar més enllà dels constrenyiments que tenim com a espècie. Així, és precisament un context més civilitzat el que permet que les persones tinguin més autonomia i llibertat perquè les necessitats bàsiques ja estan garantides; quelcom que permet més reflexivitat i tria sobre la pròpia vida, en lloc de seguir uns mandats molt marcats, sigui per via biològica o social. Una realitat que permet socialitzar tota la riquesa i la complexitat de l'herència humana a uns individus que, sense aquesta, es trobarien sempre a l'edat de pedra.

Com hem dit, el debat moral sobre la bondat o la maldat dels processos socials que toquen viure a cada generació és una constant al llarg de la història. Elias, amb Durkheim, proposa una visió alternativa al corrent dominant en ciències socials que habitualment s'expressa en aquests termes: el procés de socialització, les institucions, les relacions socials, la civilització, etc. són elements que coarten una llibertat i un individu que, sense tots aquests elements «afegits», seria més feliç i més autèntic. Per als autors francès i alemany, la perspectiva és exactament la contrària. Són precisament els elements culturals, la socialització, les institucions, etc. les que, sense oblidar la seva coerció com a preu que han de pagar, permeten construir, "produir", subjectes amb un cert grau d'autonomia, llibertat i reflexivitat respecte a les seves necessitats bàsiques. Així, el grau d'autonomia i llibertat actual només es poden entendre precisament gràcies al fet que vivim en un estadi de civilització mai vist fins ara. És el que Elias, inspirant-se en Freud, anomena «Llei fonamental del procés de la sociogènesi» i que ens ajuda a comprendre més i millor molts fenòmens actuals vinculats, per exemple, a la infantesa i a l'educació: cada infant ha de recórrer, en el seu procés de socialització, totes les etapes (estadis de civilització) per les quals han transitat els seus avantpassats. Però, en contra del professor austríac, Elias creu que aquesta llei no genera progressivament més malestar, ans al contrari, pot contribuir a aconseguir més autonomia, més reflexivitat i més plenitud dels humans, malgrat les evidents contrapartides de frustració i coerció (Collet-Sabé, 2011).

\section{Cos, persona i societat: determinació biològica o cultural?}

En el llarg debat sobre el fonament de les nostres conductes basat en la dicotomia entre natura i cultura, Elias hi té una opinió particular respecte la posició sociològica majoritària. Els seus estudis de medicina el van portar a qüestionar de manera rigorosa tant els postulats culturalistes que atribueixen pràcticament tota l'explicació del fet humà als elements apresos en societat, com els que, encara avui en dia i sota nous llenguatges (per exemple, neurociència), advoquen per un grau més o menys elevat de determinisme biològic 
sobre la conducta humana. D'una banda, el biologisme manté una postura immutable i essencialista del cos humà i creu que pot atribuir qualsevol conducta humana a la "química biològica»..., més enllà de qualsevol context cultural, social o històric. D'altra banda, els postulats culturalistes actuals afirmen que no hi ha res «essencial o natural» en l'ésser humà, sinó que tot ha estat construït històricament i socialment. Com dèiem, habitualment, la sociologia s'ha decantat més aviat cap als postulats culturalistes sense amagar un cert malestar cap al cos com a dimensió d'anàlisi incòmoda i no gaire faccil d'integrar amb els elements mentals, socials, econòmics, etc. Elias reclama amb força incloure el cos com a element d'anàlisi social. Tal com ha plantejat la psicologia de l'educació (Coll et al., 1990), el cos és el «lloc» d'una interacció constant i molt potent entre una biologia que marca condicions de possibilitat i una cultura que (re)construeix aquesta biologia, però dins d'uns certs límits.

L'autor alemany reprèn, així, algunes de les intuïcions de Freud, també amb estudis de medicina com Elias, que, a partir de la negació dels instints humans (com a pauta de conducta marcada biològicament), va trobar en la "pulsió» l'element que li permetia visibilitzar aquesta interacció tan constant, oberta i interdependent entre natura i cultura. Per a Freud, les pulsions són «energia» humana orientada però no programada, que adquireix forma i plasmació en funció de la socialització de la persona. Elias estaria en un terme mitjà semblant. El cos existeix i, malgrat que estigui en interacció constant amb la societat que és la que li dóna sentit, significat, forma, model, identitat, etc., no és neutre, ni infinit i marca condicions de possibilitat i límits. Així, Elias advoca per una nova ontologia humana en la qual la interacció oberta i canviant entre els aspectes biològics, psicològics i socials de les persones, les conductes i les relacions humanes tingui un model d'anàlisi més complex i més complet.

\section{Què és el coneixement?}

En l'article de la professora Sara Moreno (2011) sobre l'anàlisi del temps per part d'Elias, sorgeix un dels temes clau de la seva obra: Què és el coneixement? Com coneixem? Lautor alemany empra un element tan central de la vida personal i social com el temps per fer un exercici de sociologia del coneixement, una perspectiva que parteix del debat en la seva tesi amb l'epistemologia kantiana i que s'enriqueix amb una altra de les fites clau de la sociologia del coneixement, el seu company i amic Karl Mannheim. Lany 1925, Max Scheler havia encunyat el terme "sociologia del coneixement» intentant respondre al debat obert a la modernitat sobre si el pensament era quelcom "pur» o bé si estava condicionat pel context personal i social. El mateix debat iniciat per Scheler i la postura del «perspectivisme» defensada per Mannheim troben ressò en un Elias que està gestant una sociologia del coneixement força propera a la que un contemporani seu, Alfred Schütz, amb l'ajuda, primer, de Thomas Luckmann i, després, de Peter Berger, definiran com a "construccionista». 
L'axioma base de l'aproximació d'Elias seria: la realitat està (re)construïda socialment i per comprendre què és coneixement, sentit comú, avui en dia, cal una aproximació històrica des de la perspectiva de la civilització i la interdependència.

Des d'aquesta perspectiva, Elias troba un camp d'anàlisi, el temps, en el qual sembla especialment difícil defensar una proposta d'anàlisi sobre què és coneixement avui, que parteixi de la idea que la realitat és una (re)construcció social i que aquesta es pot resseguir des d'una mirada històrica i que tingui en compte els estadis de civilització diversos i el procés d'interdependència personal i social creixent. Més aviat el temps sembla una realitat, una evidència independent dels éssers humans i, per tant, un coneixement «natural», no social. Però Elias, des de la seva perspectiva, trenca amb allò evident i força una primera pregunta clau sorgida de l'anàlisi històrica del rellotge i el calendari: els instruments de mesura del temps, són «el temps»? Aquestes dues eines «reflecteixen» una realitat natural que existia abans i de manera independent dels humans, o són símbols, construccions socials naturalitzades que, una vegada fetes «objectes» se'ns imposen progressivament a cada estadi de civilització? La resposta d'Elias, presentada a l'article de Sara Moreno (2011), és molt contundent: en un món sense persones ni éssers vius, no hi hauria temps i, per tant, tampoc eines per mesurar-lo. Amb aquest debat sobre un dels elements en aparença més «naturals» com és el temps, Elias fa la "prova del cotó» de la seva sociologia del coneixement ancorada en la història, la civilització i la interdependència, una perspectiva que, posteriorment, ha estat compartida, emprada $i$ enriquida per diferents autors $i$ autores, però de la qual, per a la sociologia del segle XXI, destaquem tres elements. En primer lloc, el que Gaston Bachelard i Pierre Bourdieu van anomenar «ruptura epistemològica», Alfred Schütz considerava "anar més enllà del que es dóna per descomptat» o Wright Mills en deia la «imaginació sociològica», i que consisteix, en la pràctica sociològica, a trencar amb les evidències $i$ els prejudicis, amb els elements «naturals» $i$ «normals». En segon terme, la necessitat d'incorporar de manera metòdica la perspectiva històrica en un ofici de sociòleg que, per a Elias, està massa sovint centrat en un present cada vegada més curt. Finalment, cal destacar un tercer element que Elias, com tants altres autors, va emprar a l'hora de fer anàlisi i teoria sociològica: l'ús de la paradoxa. Entendre que, moltes vegades, els camins pels quals avança un procés al llarg de la història són de signe o de lògica contradictòria.

\section{Què fonamenta el poder personal i social?}

El poder i els poders com a centre d'interès $i$ anàlisi per part de les ciències socials és un tema certament antic. Des del naixement de la filosofia occidental a Grècia, passant pel discurs religiós oriental (hinduisme, budisme, taoisme, etc.) o occidental (cristianisme), tot el que fa referència al poder, les seves fonts, el seu (mal) ús i la possibilitat que algú faci quelcom en contra de la seva voluntat, ha estat un eix de reflexió i recerca transversal. Les professores Angela 
Perulli (2011) i Rosa Alcalde (2011), en els seus articles, aborden dues dimensions del tema del poder certament interessants: Alcalde, d'una banda, presenta el tema del «nosaltres i el vosaltres», que posa sobre la taula una reflexió sobre les bases $\mathrm{i}$ les fonts del poder en relació amb la immigració i «l'altre». Centrarem aquest debat en l'apartat 8 d'aquest article. D'altra banda, i també emprant com un dels textos base la recerca d'Elias sobre els established i els outsiders a la comunitat de Winston Parva, Perulli analitza el poder fixant-se en les desigualtats en l'estructura social, però ho fa des d'una perspectiva dinàmica i complexa. Aquesta és la perspectiva que Elias va construir a partir de preguntar-se: Per què unes persones i uns grups socials disposen d'uns recursos desiguals que els permeten mantenir una posició de poder i privilegi dins d'una societat? Quines són les fonts i les bases del poder?

La pregunta pels poders i les desigualtats va centrar molt bona part de l'envit teòric de Marx, que, des d'aleshores, s'ha convertit, sens dubte, en un punt d'anada i tornada constant en aquest vast i crucial àmbit d'anàlisi social. Marx es pregunta per les desigualtats socials i això el porta a interrogar-se sobre les bases, els fonaments, les condicions de possibilitat que fan que unes persones puguin fer la seva voluntat i d'altres, no. I la resposta que dóna se centra en el control dels mitjans de producció i la dimensió econòmica. És a dir, la principal font de poder desigual és la propietat privada dels mitjans que permeten produir riquesa per part d'alguns i no per part d'uns altres, unes desigualtats, per tant, que tenen a veure no només amb el volum dels recursos econòmics, sinó, sobretot, amb les possibilitats desiguals d'obtenir-los (classes socials). Weber recull les aportacions de Marx i, en un primer debat amb aquestes, construeix el concepte d'estatus per tal de fer veure que, malgrat que la dimensió infraestructural té un gran pes com a font de poder, no sempre és a l'origen d'aquest o no sempre n'és la «variable clau». Per estatus, Weber entén el prestigi social en diferents àmbits. Una definició que vol destacar la pluralitat de dimensions que cal analitzar com a possibles fonts de poder. És el que Bourdieu intenta operacionalitzar seixanta anys més tard, situant com a element clau de les desigualtats de poder les diverses quantitats i qualitats de capitals (econòmic, social, cultural, relacional, etc.) de cada persona i/o grup.

Norbert Elias és deutor tant de la proposta de Marx, com, sobretot, de l'esperit de la revisió i les aportacions de Weber. L'autor de Breslau genera una nova complexificació del model d'anàlisi de les fonts del poder desigual que passa pel concepte de "poder relacional»: les bases de la capacitat de fer la pròpia voluntat, que els altres facin el que jo voldria malgrat la seva oposició, no són estàtiques, sinó relacionals. No es donen en termes absoluts (disposar de cert nombre de diners, accions, habitatges, títols acadèmics, contactes, etc.), sinó dinàmics, relacionals i en (re)contrucció constant. La professora Perulli ho exposa dient que, per comprendre les fonts i les (re)construccions de les posicions desiguals de poders i recursos, Elias proposa una mirada alhora dinàmica, relacional i holística que inclogui elements macro, meso i micro, psicològics i sociològics. Per exemple, a partir de l'assaig sobre "The established and the outsiders», o sobre «The genesis of naval profession», etc., Elias remarca que 
l'anàlisi de les dimensions que resten més enllà de la racionalitat, el discurs explícit, etc. són claus. Així, els elements emocionals, la manera com les persones representen el seu entorn i es representen elles mateixes, com encaixen les expectatives pròpies i les dels altres, les experiències de relació, etc. són elements que, en relació amb els elements estructurals, van teixint els fils de les desigualtats amb un dibuix o un altre. L'exemple que veurem amb més profunditat al punt 8 és que, entre dos grups amb els mateixos recursos i poders «objectius», les fonts de poder i les relacions desiguals entre ells són donades per quin és capaç de veure's, sentir-se, comportar-se i viure com a «superior».

\section{Què és (la) violència?}

Un dels elements més interessants de la recerca d'Elias sobre el procés de civilització és la centralitat de les violències i les mutacions que presenten en el llarg avenç de les persones i les societats cap a la seguretat, les relacions «pacífiques», etc. Així, Elias exposa clarament com el fet que, al llarg de l'edat mitjana, hi hagués un procés de concentració progressiu de poder polític, econòmic i militar en determinats senyors feudals que amb el temps esdevindrien reis, va provocar, alhora, una pacificació social (menys armes, ràtzies, morts, etc.) i personal (formes més refinades, emocions més estables, etc.). En termes de Weber, el monopoli progressiu de la violència física per part del que serien els estats moderns va contribuir clarament a la pacificació personal i social. Però, només existeix la violència física o hi ha violències diverses? Quines dimensions socials pot tenir la violència? Aquesta existeix sempre i el que canvien són les formes o pot desaparèixer? Aquestes van ser algunes de les preguntes que, primer, Elias i, després, també el seu company a la Universitat de Leicester, Eric Dunning, es van plantejar en camps tan suggerents com ara el de l'esport o el temps lliure.

El professor Dunning (2011) es pregunta, en l'article del present monogràfic de PAPERS: vivim, com diu el «sentit comú», en l'època més violenta de la història? Seria aquest un indicador d'un estadi de descivilització humana que ens portaria «enrere» en els «avenços» en (auto)control, pacificació, etc.? Dunning creu que no només estem en el moment històric amb menys violència (dimensionada en elements físics: guerres, genocidis, crims, etc., i no físics: agressions verbals, psíquiques, violència simbòlica etc.), sinó que precisament aquesta experiència de la negativitat de qualsevol conflicte, aquesta creença que vivim el moment més violent de la història, etc. són indicadors d'una societat que apunta i desitja un impossible: el final absolut de qualsevol violència i de qualsevol conflicte. És més, tota la tradició psicoanalítica des de Freud fins a Erich Fromm, de la qual també beu Elias, situa la pulsió agressiva no només com a constitutiva de l'ésser humà, sinó, a més, com un element que pot ser positiu i que permet que la persona i el grup es defensi, s'afirmi i fins i tot es doni identitat. L'exemple treballat per Elias i Dunning (1992) del rol de l'esport com a canalitzador civilitzat i positiu de la violència entre estats i grups en seria un bon exemple. 
Elias i Dunning, al llarg de la seva trajectòria acadèmica, han fet recerca al voltant de les dues hipòtesis sobre la violència que van anar desenvolupant. La primera és que hi ha diferents tipus de violència i que totes responen a la natura humana. Cal prendre-les com a part de la naturalesa humana, amb les possibles vessants positives i negatives que presenten, tot evitant la càndida perspectiva del «bon salvatge», que considera la persona com a "pacífica» per essència. La segona de les hipòtesis és que l'anàlisi i la recerca sobre les violències en camps com ara l'esport i el lleure són altament il.luminadores i permeten identificar variables i conductes, sovint difícils d'operacionalitzar en l'estudi dels grans processos socials com ara la individualització, la civilització, etc.

\section{Qui és l'altre?}

L'anàlisi de l'altre, de l'estranger, del foraster, de l'outsider..., així com les moltes o poques possibilitats de "viure junts», ens ha regalat algunes de les millors pàgines, tant de la literatura com de les ciències socials al llarg del segle XX. Així, la idea que existeixen persones i grups que em són «estranyes», diferents, «altres», i l'experiència de la vida en comú ha estat un dels temes més punyents del segle XX que, segons sembla, seguirà essent clau en la sociologia del segle XXI. Norbert Elias i John L. Scotson (1965) s'apropen al procés de construcció social del foraster, de l'estrany, en una recerca molt especial. Tal com analitza la professora Alcalde en el seu article (2011), en lloc de seguir el camí habitual de situar-se en un context entre dos grups o comunitats amb un diferencial de recursos significatiu, Elias i Scotson busquen analitzar el fons de la qüestió de la construcció de l'alteritat, l'estrangeria i la desigualtat entre dos grups amb recursos objectius iguals. És precisament aquesta perspectiva la que, en un segon moment, permet a Alcalde ressituar i recentrar l'agenda de la sociologia de les migracions en els aspectes centrals de relacions de poder en vista de les aportacions d'aquesta recerca.

A la comunitat de Winston Parva, com es construeix l'estigmatització dels nouvinguts, malgrat que també siguin autòctons, blancs i amb recursos econòmics i culturals semblants als dels establerts que ja hi vivien? Els nouvinguts a la comunitat no són pobres, ni de cap ètnia «diferent», ni roden pel món, etc., són persones arribades a una zona residencial. Així, Elias i Scotson poden analitzar quina és la "quintaessència» del procés social de construcció del marginat, de l'outsider, del foraster, sense els perills ni les justificacions que habitualment se situen com a origen d'aquest procés. El principal estigma que cau sobre l'altre i que el manté com a «foraster perillós», com a «enemic» del «nosaltres», és que no comparteix els supòsits bàsics del nostre grup i, per tant, constitueix una amenaça alhora perquè es pugui cohesionar (contaminació) i perquè pugui continuar (destrucció de la pròpia identitat). La força de l'estigma és, com assenyalen tots els autors que han treballat el tema, que la «víctima» incorpora la mateixa definició de la realitat que els estigmatitzadors. És el que Bourdieu anomena «violència simbòlica» (1994): quan accepto que sóc un estigmatitzat o bé canvio i faig "com els establerts»; bé resto «apàtic»; o bé 
acompleixo la profecia que s'ha llançat sobre meu i em comporto com un outsider, és a dir, trenco normes i m'autosituo com un «diferent». En el cas concret analitzat per Elias i Scotson, els mecanismes i els recursos per poder generar i mantenir aquesta violència simbòlica són molt subtils $i$, alhora, constitueixen el cor de qualsevol procés d'estigmatització: les normes, els vincles personals i emocionals, la coherència grupal i el control col-lectiu dels establerts.

Així, una de les pistes clau d'Elias i Scotson en aquest àmbit, com ens recorda Alcalde, és la necessitat de generar recerca empírica, concreta i territorialitzada dels processos d'estigmatització, segregació, etc. Un dels possibles errors actuals en aquest àmbit rau a centrar la recerca només en discursos genèrics, sense vincle ni focalització en aquelles pràctiques, mecanismes i relacions individuals, comunitàries i socials concretes que són les que (re)construeixen l'estigma, la separació desigual entre el «nosaltres» i els «altres». La pràctica sociològica d'Elias ens convida a no oblidar aquesta dimensió en la recerca sobre els processos d'estigmatització.

\section{Qui és el malalt o la malalta?}

La línia que separa la salut de la malaltia és, evidentment, una construcció social i històrica que evoluciona amb el temps, però el resultat d'aquesta construcció situa uns grups de persones dins de la categoria de «sans» i uns altres, dins de la categoria de «necessita tractament». Els uns resten dins de la "normalitat» i per a d'altres "cal» preveure un seguit d'estratègies educatives, psicològiques, mèdiques i socials per tal que hi retornin. Així doncs, la pregunta sobre qui és considerat malalt o necessitat d'algun tipus de teràpia, cura $o$ reequilibri, no és banal en cap sentit. No ser considerat «normal» en un context social acostuma a ser font de conflictes, tractaments i violències. Elias ho analitza amb finor en el seu famós El proceso de la civilización (1987), on aporta molta llum als conceptes inextricables de normalitat i desviació des de la teoria de la civilització: en funció de quin sigui l'estadi de civilització en el qual ens trobem, el model normatiu de «normalitat o desviació» serà diferent, així com les mesures que cal prendre per retornar la persona i/o el grup social al «bon camí».

La professora Helena Béjar (2011) treballa des d'aquesta perspectiva construïda per Elias per tal d'analitzar, en els nostres dies i en relació amb el model ideal actual de persona individualitzada, quines pautes humanes poden ser considerades «desviades» i, sobretot, se centra en què i com se'n planteja la «millora». El context civilitzador actual marca idealment que cada persona és absolutament responsable de tota la seva vida: d'estar sa o malalt, de tenir èxit o de fracassar a l'escola, a la feina, en l'amor, etc. Com Elias ja analitzava, ens trobem davant de la màxima expressió històrica de la pressió civilitzadora en l'actual «societat dels individus». En paraules de Zygmunt Bauman (2001), cadascú és l'únic responsable del que li passa a la vida, amb la qual cosa fa cada vegada més opacs tots aquells mecanismes socials i estructurals que situen desigualment les oportunitats i els recursos vitals. És en aquest context en el 
qual, segons Béjar, l'autoajuda esdevé el nou «codi psicològic» hegemònic d'acord amb l'estadi de civilització i el model de persona actual: si cadascú és responsable absolut de la seva vida, sembla lògic que tothom es preocupi per com pot millorar-la, com pot ser feliç, com pot triomfar a la feina, en l'amor, etc. Si Elias havia emprat els manuals de conducta i d'educació medievals i moderns com a indicadors per comprendre el model de persona imperant en aquella època, les línies que separaven la normalitat de la desviació i els mecanismes de curació, etc., Béjar proposa emprar els manuals d'autoajuda contemporanis en el mateix sentit.

L'esquema analític d'Elias en aquest àmbit ens sembla, amb Béjar, més necessari que mai: cal ser conscients que les línies que delimiten la normalitat de la desviació i la salut de la malaltia són una reconstrucció social fràgil, dinàmica i canviant, i estan en relació amb les exigències, les normativitats i els models personals, socials, educatius, amorosos, laborals, religiosos, etc. de cada estadi civilitzador. Així, Elias convida la sociologia del segle XXI a estar més atenta que mai a analitzar aquestes "línies» des d'una perspectiva històrica, contextual i dinàmica, fugint dels essencialismes sincrònics que tan útils són per etiquetar de manera definitiva la realitat $\mathrm{i}$ les persones, però que tan poc serveixen per comprendre-la i generar condicions de possibilitat de benestar.

\section{A manera de conclusió: l'artesania de fer sociologia}

La pràctica de la sociologia entesa i proposada com una artesania no és una invenció d'Elias. Abans, durant i després de l'autor de Breslau, han estat molts els que han exemplificat, a través de la metàfora de l'artesà (Wright Mills, 1987; Sennett, 2009), el què i el com s'hauria de desenvolupar la tasca sociològica. Creiem que, per a Elias, aquesta artesania sociològica té tres principis clau, algun dels quals no està precisament en consonància amb l'actual model hegemònic de científic social en el nostre estadi de civilització. En primer lloc, Elias reclama que, per tal de construir una bona recerca, més que no pas fer un repàs exhaustiu a tota la bibliografia precedent i una acumulació de citacions en els treballs, el que cal és realitzar una reflexió aprofundida i pròpia sobre el tema escollit. Així, l'autor alemany posa en qüestió el «criteri d'autoritat» que representa citar algú precedent i/o amb un prestigi acadèmic superior o igual. I predica amb l'exemple: al llarg de Teoría del símbolo (1994), Elias només fa una citació d'altres autors; i a les més de cinc-centes pàgines d'El proceso de la civilización (1987), només fa una citació per reconèixer el mestratge de Max Weber i una altra per explicitar el deute teòric amb Sigmund Freud. Diferents circumstàncies històriques i elements de la seva personalitat poden explicar aquesta actitud que a nosaltres ens sembla extrema. Però no és menys cert que Elias ens aporta un toc d'atenció a una cert model de recerca actual que requereix haver fet un repàs tan exhaustiu a l'estat de la qüestió d'un tema, que les pròpies aportacions, interessos, interrogants i debats poden arribar a desaparèixer. Segurament, un terme mitjà que situï un estat de la qüestió acurat, un envit propi i original i un reconeixement equilibrat a les evidents i múltiples apor- 
tacions d'autors precedents, ens sembla un bon plantejament per a l'artesania sociològica, malgrat que Elias segurament no el compartiria.

El segon dels centres d'interès d'Elias a l'hora de proposar com es pot practicar la sociologia és la necessitat d'una perspectiva, d'una teoria global que pugui donar sentit als indicis, a les teories de mitjà i curt abast, a les dades inconnexes, etc. L'autor de Breslau, amb la seva proposta de la teoria de la civilització, primer, i de la sociologia figurativa, després, presenta un relat, una metàfora, un marc ontològic, epistemològic i metodològic general (Lakoff i Johnson, 1999). Des d'aquest marc, Elias es llança a una recerca coherent i recíprocament fecunda en àmbits tan dispars com la construcció de l'estigma, la violència en l'esport, la figura de Mozart, el temps, la civilització dels progenitors i dels infants, els alemanys o els moribunds. Finalment, el tercer dels elements clau per a Elias a l'hora de treballar amb la sociologia és la necessitat de fer, en diàleg constant amb aquest marc general que es vol (re)construir, recerca empírica que impliqui treball de camp, lectures, entrevistes, anàlisi de documents, anàlisi estadística, etc.

Segurament, de tot el que hem intentat exposar en el present article de manera incompleta i parcial, els dos elements més importants són, d'una banda, les preguntes. Creiem que, com tots els clàssics, Elias encerta les preguntes i això és el que fa que les seves aportacions, algunes de les quals van ser emeses fa setanta anys, segueixin essent rellevants, significatives i estimulants. L'altre element especialment significatiu és el model de concebre i practicar la sociologia com una artesania. Un model que inclou una perspectiva teòrica potent en relació constant amb unes anàlisis empíriques originals. Totes dues són pistes que ens semblen interessants per a la sociologia del segle XXI de part d'un clàssic del segle XX.

\section{Bibliografia escollida de Norbert Elias}

En aquest apartat, hi proposem només algunes de les obres d'Elias que, per l'interès que tenen, creiem que poden ser bones portes d'entrada i/o aprofundiment en la seva perspectiva per a persones que encara no han tingut contacte directe amb l'obra de l'autor de Breslau.

a) ELIAS, Norbert (1987). El proceso de la civilización. Mèxic: Fondo de Cultura Económica.

És la seva obra magna, la més llegida i coneguda. Fonamenta i alhora posa en pràctica tota la perspectiva i el programa de recerca de l'autor alemany.

b) ELIAS, Norbert (1987). La sociedad de los individuos. Barcelona: Península. Llibre constituït per textos d'èpoques diferents. Aquesta obra situa clarament algunes de les bases teòriques principals de la sociologia d'Elias.

c) ELIAS, Norbert (1990). Compromiso y distanciamiento. Barcelona: Península. En aquest treball, Elias reprèn el clàssic debat entre l'engatjament $i$ la distància, intentant trobar el punt òptim de proximitat a l'objecte d'estudi per fer bona recerca.

d) ELIAS, Norbert (1998). La civilización de los padres y otros ensayos. Bogotà: Norma. Llibre eclèctic de diferents textos d'Elias que permeten tenir una visió panoràmica de l'autor i la seva anàlisi de temes diversos, actuals o històrics. 
e) ELIAS, Norbert (2003). «Ensayo acerca de las relaciones entre establecidos y forasteros». Revista Española de Investigaciones Sociológicas, 104 (3), 219-251.

Aquest és un resum força complet del mateix Elias de la seva obra The established and the outsiders, ja referenciada en els articles de Perulli i d'Alcalde d'aquest número de PAPERS.

f) Elias, Norbert i DunNing, Eric (1992). Deporte y ocio en el proceso de la civilización. Méxic: Fondo de Cultura Económica.

En aquest llibre, Elias i Dunning enceten una perspectiva d'anàlisi civilitzadora sobre l'esport i el lleure que continua avui en dia de forma molt fructífera.

\section{Bibliografia escollida d'obres sobre Norbert Elias}

Monogràfics de revistes:

Theory, Culture \& Society, 4 (2-3), 1987.

Revista Española de Investigaciones Sociológicas, 65, 1991.

Llibres:

HeInICH, Natalie (1997). La sociologie de Nobert Elias. París: La Découverte.

VAN KRIEKEN, Robert (1998). Norbert Elias. Londres: Routledge.

Bonny, Yves; De QueIROZ, Jean-Manuel i Neveu, Erik (eds.) (2003). Norbert Elias et la théorie de la civilisation. Rennes: Presses Universitaires de Rennes.

LeYva, Gustavo; Vera, Héctor i ZabludOvsKY, Gina (2002). Norbert Elias: legado y perspectivas. Mèxic: Lupus Inquisitor.

LoYAl, Stephen i QuILley, Stephen (eds.) (2004). The sociology of Norbert Elias. Cambridge: Cambridge University Press.

Quilley, Stephen (ed.) (2006). Complete works of Norbert Elias. Dublín: UCD Press.

ZABLUDOVSKY, Gina (2007). Norbert Elias y los problemas actuales de la sociología. Mèxic: Fondo de Cultura Económica.

\section{Bibliografia de l'article}

AlCAlde, Rosalina (2011). «De los outsiders de Norbert Elias y de otros extraños en el campo de la sociología de las migraciones». Papers: Revista de Sociologia, 96(2), 375-387.

BAuman, Zygmunt (2001). La sociedad individualizada. Madrid: Cátedra.

BÉJAR, Helena (2011). «Cultura psicoterapéutica y autoayuda. El código «psicológico-positivo». Papers: Revista de Sociologia, 96(2), 341-360.

Bourdieu, Pierre i WaCQUANT, Loïc (1994). Per una sociologia reflexiva. Barcelona: Herder.

CAstillo, Juan-José (2009). «Seguir a los clásicos: un taller oculto en la formación del sociólogo». Política y Sociedad, 46 (3), 77-90.

Coll, César; MARChesi, Álvaro i PALACIOS, Jesús (1990). Desarrollo psicológico y educación. Madrid: Alianza.

Collet-SabÉ, Jordi (2011). «Norbert Elias. Una proposta d'intellectual portrait vint anys després de la seva mort». Papers: Revista de Sociologia, 96(2), 285-308. 
DunNing, Eric (2011). “Testing’ Elias: Aspects of Violence Viewed in Long-Term Perspective». Papers: Revista de Sociologia, 96(2), 309-339.

Elias, Norbert (1987). El proceso de la civilización. Mèxic: Fondo de Cultura Económica. - (1994). Teoría del simbolo: un ensayo de antropología cultural. Barcelona: Península. Elias, Norbert i DunNING, Eric (1992). Deporte y ocio en el proceso de la civilización. Mèxic: Fondo de Cultura Económica.

ELIAS, Norbert i SCOTSON, John L. (1965). The established and the outsiders: A sociological enquiry into community problems. Londres. SAGE.

García de LeÓn, María Antonia i FíGAREs, María Dolores (2009). Antropólogas, politólogas y sociólogas. Barcelona: Plaza y Valdés.

LAKOFF, George i JOHnSOn, Mark (1999). Philosophy in the Flesh: The embodied mind and its challenge to Western Thought. Nova York: Basic Books.

Madoo Lengermann, Patricia i Niebrugge-Brantley, Gillian (1998). The Women Founders. Sociology and Social Theory 1830-1930. Nova York: McGraw Hill.

MorenO, Sara (2011). «L'empremta de Norbert Elias en l'estudi sociològic del temps». Papers: Revista de Sociologia, 96(2), 361-373.

GARCÍA MARTíneZ, Alejandro Néstor (2011). «¿Distinción social o sociabilidad pura? El impulso civilizador en los salones aristocráticos y burgueses, según Elias y Simmel». Papers: Revista de Sociologia, 96(2) 389-408.

SENNETT, Richard (2009). El artesano. Barcelona: Anagrama.

Wright Mills, Carl (1987). La imaginació sociològica. Barcelona: Herder. 